\title{
INTENÇÃO DO AUTOR, VONTADE DO AUTOR OU LÓGICA DO TEXTO.
}

Philippe Willemart (*)

\begin{abstract}
RESUMO
Esre artigo trato de dessacralizar as conceitos de escritor e de autor, e restabelecer asstm a primaria da logica do texo sobre as intençöes supartas do autor na melhor tradlç̧o da Aufklörong

Unllermos: autor, escritor, manuscriso; variante.
\end{abstract}

Os estudiosos do manuscrito literário, que tentam estabelecer a ediçăo critica de um texto já publicado, se deparam frequentemente com várias versóes de um mesmo texto, capitulo, parágrafo ou palavra e se perguntam qual criterio adotar para escolher tal ou tal liçao. Quase sempre o escritor já morreu e o crítico é levado a considerar a obra como uma herança e o manuscrito ou a última ediçăo como seu testamento.

Nesse clima funéreo, o crítico, desejando respeitar o desejo do morto, procura, tal um testamenteiro, cumprir as últimas disposiçoes do falecido e recorre ao que é chamado tradicionalmente a última vontade do autor. De fato, deveríamos dizer a última vontade do escritor, já que se refere habitualmente à vontade do homem vivo, seu ego e suas intençóes e năo ao autor que assina o texto.

Esse clima trágico envolve normalmente o pesquisador debutante e o mantém em uma atitude respeitosa que frisa às vezes a adoraçăo

- Protessar Titular de Literatura Francesa no Depto, de Letras Modernas (FFLCH/USP) e Membro Fundador da Associsçło dos Pesquisadores do Manuscrito Literário.(APML) 
quando toca os manuscritos. Nåo sem razåo. O escritor é na maioria das vezes reconhecido por seus contemporaneos ou pela critica como um ser singular e genial, e sua herança manuscrita, além de deixar o consultor fascinado, impóe um respeito bem maior do que a obra publicada aberta para todos. Além do mais, o acervo, conservado na maioria das vezes em instituiçóes públicas, é mantido em arquivos ou em cofres ao abrigo da luz e da poeira, numa temperatura determinada, o que lembra bastante a mumificaçáo dos egipcios ou o processo de refrigeraçăo do freezer, ampliando assim seu aspecto sacralizado e tumular.

Mas, apesar desse clima sagrado que rege normalmente as relaçס̋es do conservador com o manuscrito, o pesquisador ousa "tocar" 0 objeto.

Digo tocar e nåo manejar ou folhear, porque tocar reflete melhor o sentido sensual desse apalpar que lembra os primeiros passos de uma relaçăo amorosa.

Năo se trata, no entanto, de uma relaçăo amorosa de igual para igual, nem de pai para filho ou filha. Nesse primeiro contato, estabelece-se uma relaçăo de amante para amado, na qual o crítico é o amante e o manuscrito é o amado. Só que o objeto digno do amor oferece uma enorme vantagem sobre qualquer outro objeto digno de amor. Ele está parado, imóvel, entregue totalmente às mãos do crítico, oferecendo apenas uma resistencia leve com as rasuras, mas nåo se dispersa e não se desintegra, salvo se for mal conservado. Sua permanencia e sua unidade săo fatores de segurança que tranquilizam o critico e lhe dão confiança no futuro da relação. $O$ crítico pode procurar à vontade "no objeto de seu desejo" os processos de criaçăo, os mecanismos da invençăo ou os meandros da formaçăo da escritura; o objeto nunca será desvelado totalmente porque, qual a dama inacessivel dos trovadores, o amado manterá sempre o mistério e uma distância proporcional a coragem do pesquisador.

Entretanto, a medida que o trabalho de deciframento e de classificaçăo prossegue, o amado inverte a relaçăo e aos poucos impōe seus desejos ao amante. Ele começa a ditar as regras, a dizer que é assim que se escreve, que se fala e que se compó, e envolve o pesquisador na sua história até que, por um processo curioso, o critico vira amado e o manuscrito, amante. A lei muda de posiçăo e o pesquisador, humildemente, aprende com o manuscrito novas regras do jogo.

Enquanto dura esse processo, a figura do escritor falecido continua se impondo, e dificilmente se desliga de seu texto para o crítico. No começo, a situação não estava clara porque, ao mesmo tempo que o manuscrito tomava a posiçáo do amado, a figura do escritor, embora nāo intervindo, pairava acima vigiando imaginariamente a relaçăo como se estivesse incumbido da observância de certas leis. Mas, com a mudança de posiçăo, a figura do escritor só reforça a situaçăo do 
amante e de mando ocupada pelo manuscrito e parece falar junto, senăo no lugar do manuscrito. Assim nasceu esse critério da última vontade do autor (do escritor) que justifica uma impostura. $O$ escritor, que tinha abandonado seu texto ao público e ao crftico, retoma posse de seu texto indevidamente, como se fosse vivo, e continua reinando através de suas supostas intençôes, isto e, supostas pelo critico no deciframento do manuscrito. É um abuso de poder do morto que aproveita a fama da obra para imiscuir-se na escrita do critico. Essa associaçăo Intima e enganosa do escritor para com o autor surge na modernidade e está ligada historicamente ao advento do Iluminismo no século $X V I I I$, que inspirou a lei dos direitos autorais.

A propriedade intelectual foi legalizada em 1791 na França pela lei Le Chapelier, que rezava: $A$ mais sagrada e a mais pessoal de todas as propriedades é a obra, fruto do pensamento de um escritor. Em 1793, essa lei foi completada pela lei de Lakanal, que concedia os direitos autorais durante 10 anos, prazo que foi estendido para 50 anos em 1866. Juridicamente, portanto, a obra pertence ao escritor $e$ a seus herdeiros e năo pode ser editada sem sua autorizaçăo. Sabemos, no entanto, que o legislador apenas confirmou um estado de espirito decorrente náo só da institucionalizaçăo dos ideais burgueses revolucionários, mas do contexto anunciador dessa revoluçáo, o século das Luzes.

O século XVIII, que dessacralizava a Bíblia e os santos, os dogmas e as verdades imutáveis, a história e a ciéncia, provocou ao mesmo tempo um movimento inverso, a personalizaçăo e a sacralizaçăo do autor.

O honnếe homme culto da elite se separa do povo de Deus e a Igreja năo consegue cristianiza-lo. l.../ Mas ele produz imagens novas e um catecismo leigo movido por uma furiosa necessidade de acreditar, de honrar, de inventar ldolos, de comemorar. As elites incrédulas, familiares da crítica, tinham um esplrito de notavel seriedade para com seus proprios totens. O culto dos grandes homens é o elemento central do novo catecismo.(1)

O grande homem garante a tradiçáo, a transmissáo simbólica e a simbolizaçăo.(2) O Panteấo substitui os santos da Igreja e o genio supremo é destacado como valor supremo. Há uma aliança intrinseca entre a razáo, o genio e a luta contra os preconceitos incutidos pela autoridade religiosa na interpretaçáo das Santas Escrituras ou pela

1 BONNET, Jean-Claude. Naissance du Phantheon. Potique Paris, Seuil. 1978. 33. pp.
46-47.

2 Id. Ibid, p. 55. 
precipitaçฐo no julgamento que impede de perceber a novidade embutida no texto.(3)

Entretanto, essa valorizaçăo do escritor năo se explica somente pelos novos clérigos da cultura que substltuiram os santos da Igreja, mas decorre também da automatizaçáo do sujeito, resultado do desligamento do sujeito da tradlçăo, iniciado por um dos inspiradores do século das Luzes, René Descartes. Ele afirma no seu Discurso do método que seu projeto năo é ensinar aqui o método que cada um deve seguir para bem conduzir sua razāo: mas apenas fazer ver de que maneira tratou de conduzir a sua. (4) Sua primeira regra: năo aceitar jamais como verdadeira qualquer coisa sem antes a conhecer evidentemente como tal (5), submete qualquer acontecimento ao crivo da razåo e da subjetividade descartando as visóes anteriores da filosofia e da ciencia.

O século XIX, por sua vez, abrange dois movimentos. Enquanto a filosofia positiva tenta impor a razáo e a ordem em todos os campos da ciéncia excluindo o sujeito pesquisador, o romantismo, já iniciado no final do século XVIII, idealizava o homem e destacava seus sentimentos, seus sonhos e seus devaneios. A criaçåo individual, o ego do escritor, a crftica impressionista, o papel polftico de muitos escritores na sociedade sáo elementos fundamentais na república das letras. Há uma exacerbaçăo do indivfduo, as custas da tradiçâo e do contexto cultural imediato, que responsabillza o sujeito escritor por suas obras, vistas como expressão de seu gênio.

Em 1870, Rimbaud lança seu famoso "Je est un Autre " que contribuirá para submeter o escritor à sua escritura e a desligar o sujeito escrevente do sujeito enunciador. No final do século, Sigmund Freud, confirmando a frase de Rimbaud, define um sujeito submetido ao inconsciente e consagra sua divisão ou sua fragmentaçăo. A unidade do sujeito é imaginária e efeito de uma projeçáo. O ego é constitufdo de uma reunião de projeçōes-idealizaçð̌es.

Jacques Lacan, relendo Freud, vai um pouco mais longe e subjuga o ser falante a linguagem. Nós somos falados e forçados a usar a sintaxe e gramática da língua. O escritor $€$ um efeito da linguagem tanto quanto sua obra. Como qualquer falante, ele entra na linguagem e se faz objeto dela mesmo antes de criar sua obra. As posiçס́s estáo invertidas. O sujeito é reconhecido e identificado por seu nome ou pelas marcas deixadas na cultura, sua obra, e năo pela soma de açóes muitas

3 GADAMER, Hans-Georg. Verite et methode Parts, Seuil, 1976. pp. 110 e 117.

4 VALÉRY, Paul. Discurso do melodo. O pensamento vivo de Descantes Săo Paulo, EDUSP/Lvraria Martins editora, 1975 p. 38.

5 Id. Ibid, p. 49. 
vezes fragmentadas de sua vida. A cultura dá a retaguarda à posiçăo do sujeito. A reviravolta é total e o romantismo fica esquecido.

Os estudos do manuscrito não só confirmaram essa revoluçắo rimbaldiana e esses dados da psicanálise mas demonstraram uma mudança ainda maior. $\mathrm{O}$ manuscrito revela no decorrer das campanhas de redaçoes, ou mesmo, no caso de Guimarkes Rosa, quando passa dos dicionários e das listas para a escritura, a transformaçao do escritor em scriptor.(6) Procurando inovar, e nessa disposiçăo e busca está seu genio, o escritor se torna instrumento da escrita e náo seu sujeito. A serviço da língua contemporánea, dos provérbios e ditados, dos modos de falar artesanais ou regionais, da historia da língua, de sua etimoiogia, das tradiçoes, da cultura e dos anseios de seu século, o escritor năo procura apropriar-se desses bens culturais e náo se considera portavoz de intençoes e vontades pessoais. Quando Guimarăes Rosa em Bicho Mauconstrói a palavra jiboicamente ou sinuoseando, está usando recursos de sintaxe e de lexicografia, que já sugerem um sentido prefixado pela tradiçáo. Pelo contrário, quando inventa a palavra cochléas, a justifica escrevendo:

" do grego" koklios" ; já tinhamos " cóclea ", mas é chôcho, fiz o belo cocleia e ainda pretendo usar a outra forma, mas melhorada em cócla. Usei no sentido de concha do gasterópodo. Enriqueçamos: "caracol "fica para o molusco; "cocleia", "cóclea " $e$ " cocla "para a sua calcárea residenciazinha respectiva".(7)

Ele reconhece a origem da palavra, mas ignora a palavra latina $c o$ chlea muito proxima da palavra criada e que significa caracol; todavia, reserva a palavra nova para a casa do caracol, dando-lhe assim um sentido proprio.

O escritor reconhece sua dependencia do autor e não faz questáo de impor seus desejos. E, se fizer enquanto vivo, usará seu poder de proprietário confirmado pela lei, confundindo talvez o direito de receber direitos autorais com o de posse de um objeto que se tornou público

6 Dintiguimos o escritor, do scriptor e do autor. $O$ exritor é, por exemplo, Honoré de Balzac, filho de $x$ e $y$, que estudou em Tours e fez direito em Paris, que defendia o poder aristocritico, etc $O$ seriptor 6 Honore de Balzac que, se submetendo ao processo escritural, sotreu transformap̧bes inicialmente năo previstas no decorrer da escritura, coagido pela linguagem, pelo mundo inventado e pela tradiçaso. $O$ autor 6 a instancia que decide náo mais rasurar tal paragrafo ou palavra, que aceita e confirma o texto "definitho" e assina Honore de Balzac antes de entrega-lo ao editor.

7 Guimardes Rosa. Série Originais, pasta no. 25. Arquivo Guimaráes Rosa. Instituto de Estudos Brasileiros. Citado por Maria Neuma Barreto Cavalcante. Bicho Maut A genere
de um conta. 1991 (FFLCH/USP, Tese de Doutorado). 
desde sua publicaçăo, como a palavra o indica. Da mesma maneira, o crítico que se baseia nas intençбes do escritor encontradas na correspondencia ou nas entrevistas com familiares, esquece tanto a natureza pública desse bem quanto a sua essência. Há uma contradiçăo evidente entre o fato de poder manipular o manuscrito conservado em instituiçóes públicas e a vontade de encontrar unicamente uma intençâo pessoal nesta ou naquela rasura.

Como podemos então determinar a intençåo do autor se temos que fazer abstraçăo da última vontade do escritor?

O exame da tinta e do papel, o recorte de circunstancias da vida do escritor ou de fatos contextuais, a leitura da correspondencia, ou mesmo uma consulta a parentes ou amigos, ajuda as vezes a datar o manuscrito, tal ou tal paragrafo. Mas, frequentemente, essa crítica externa se revela inadequada para determinar a cronologia das versoes e totalmente inapropriada para fixar o sentido de uma seqüencia ou de uma palavra. $O$ editor crítico deve recorrer a crítica interna que obriga a estudar o texto no qual $a$ vontade do autor se manifesta.

E aqui temos que explicar melhor o conceito de autor, praticamente sinónimo de coerência do texto. Se encararmos o texto publicado como uma série de trechos concluídos que, articulados, formam o capitulo, identificaremos a instancia do autor aquele que conclui, isto $\hat{e}$, àquele que decide năo mais rasurar e continuar adiante na sua escritura. $O$ estudo do texto ou de trechos do texto publicado mostra uma lógica inerente a cada um deles. $O$ exame minuncioso do que foi chamado variante, demonstra que ela năo é uma simples substituiçăo de uma palavra por outra, mas uma outra lógica que se instala ou é recusada. A logica semantica rege a maior parte desses trechos, mas a lógica literal, lúdica, fônica, sintática, das cores, do tempo etc. age também. É nesse sentido que Bernard Cerquilini preferiu a palavra variance à variante (8) A variante, ligada demais a filologia e a crítica textual, sugere uma possibilidade logo afastada pelo escritor, um desvio lido como resto ou como imperfeiçăo em relaçăo ao texto publicado. E uma visão teleológica do texto. Nesse caso, o crítico leva em conta a intençăo do escritor na sua ansia de perfeiçăo. A "variance ", pelo contrário, considera a palavra ou o parágrafo novo como um caminho possivel que abre outros mundos porque movido por outra lógica, que náo está na cabeça do escritor, mas no texto. Se Guimarăes Rosa transforma palavras ou junta morfemas de línguas diferentes, nåo é a sua intençáo de inovar o que nos preocupa - inovar ou renovar é próprio dos artistas - mas o processo de transformaçăo. Perguntamo-nos năo so quais foram os caminhos seguidos para chegar ao texto ou qual e a parábola ou os meandros que dirigiram o scriptor do dicionário até o

8 CIRQUILINI, Bernard. Eloque de la variarte (Histoire critique de la philologie). Parts, Seuil, 1989 (col. Des Travaux). 
texto, mas também qual foi a logica da língua que deu esse resultado. O como e o porqué interessam ao estudioso da gênese. A ciencia e a filosofia fazem parte da pesquisa genética.

Podemos nos perguntar, para terminar, porque identificamos táo facilmente a última vontade do autor com a intençáo do escritor, confundindo assim abusivamente o texto com o homem que o escreveu.

Apontei uma razăo histórica, essa substituiçáo dos clérigos e santos da Igreja retirados dos altares pelo racionalismo das luzes. $O$ povo, letrado ou nao, precisa de objetos identificadores que indicam caminhos e dáo exemplos para as geraçōes futuras. A funçăo identificatória e pedagógica parece imprescindfvel numa sociedade. Os gregos tinham suas divindades, os cristáos seus santos e o homem moderno seus genios, artistas polfticos, cientistas etc. Inserido na sua cultura, o crítico náo escapa a essa identificaçăo e associa facilmente o escritor ao autor, os fatos da vida ao texto publicado. Dissociamos dificilmente a biografia do escritor de sua obra e continuamos achando por um efeito narcfsico que o escritor manda na sua obra. Mostramos, pelo contrário, que a fonte principal da formaçăo da obra se encontra na linguagem, na história e na tradiç̧o e que a vida do escritor $\epsilon$ apenas um dos elementos desta formação. Há, no entanto, mais um dado que impede essa dissociaçđo.

A psicanálise, analisando a formaçåo do ego, mostrou que a criança quando ainda náo pode andar nem falar já encontra a unidade de seu corpo através de sua imagem no espelho, portanto através de uma virtualidade ótica, imaginária e nåo real. A partir dessa forma vista, se inicia um processo de identificaçăo, que consistirá em juntar, ao redor dessa imagem, elementos encontrados nos parentes e amigos ate chegar a constituir sua identidade. Embora nao dispondo ainda de sua motricidade e da fala, fragmentária ainda, a criança consegue se firmar através de uma imagem à qual a máe atribui o nome dela, criança, consolidando sua "personalidade". Assim também nascerá sua agressividade, que consiste em recusar as imagens dos outros que entrem em conflito com ele na disputa pelo amor do pai ou da má. O mesmo processo se repete no decorrer da vida. Disperso entre suas funçð̌es familiares, profissionais e sociais, o homem, graças ao nome e ao sobrenome que o significam, tem o sentimento de permanecer o mesmo desde o nascimento, apesar da sua fragmentaçáo, inerente à vida moderna. No entanto, esse vai-e-vem entre a imagem e o nome, entre esse esforço de juntar seus pedaços e sua inserçáo na língua e na cadeia parental pelo nome, continua em todas suas atividades como adulto. $O$ texto, seu ou dos outros, se torna assim um dos meios para se espelhar e encontrar sua unidade. O texto reveza os outros homens-espelhos e o espelho da infancia. $O$ crítico năo atento, sempre à procura de sua unidade como qualquer homem, se deixa enganar pela coeréncia do texto. Nåo só ele se vê no texto, mas atribui essa unidade real ao autor que o assinou, o que năo estaria errado, se nāo confundisse, se soubes- 
se distinguir o escritor do autor. Alguns autores, conscientes ou năo dessa dupla funçăo, assinaram com um pseudónimo, Henri Brulard por Stendhal, Frederic Sauser por Blaise Cendrars, o que năo impediu evidentemente muitos criticos de ler a obra a luz da vida deles. O deslize quase automático do autor para o homem, que alguns críticos fazem, provoca o endeusamento do escritor, a veneração por seus objetos, a instalaçăo de sua biblioteca em museu, a coleçăo de álbuns de fotografia, a constituiçăo de uma sociedade de amigos de... etc.

Em outras palavras, se o critico năo lutar contra ele próprio e contra o ambiente historicizante e hagiografico que geralmente cerca os escritos e os objetos do poeta ou do ficcionista terá dificuldade em encontrar seu desejo fora da vida do escritor e confundirá sempre a intençăo do escritor com a vontade do autor. Todavia, para evitar essa assimilaçåo do autor ao escritor, quase inevitável, talvez seja melhor esquecer a vontade do autor e falar em lógica do texto.

Recebido em 10/7/91

\author{
ABSTRACT \\ An article about the concepts of writer and wuthor considering the printacy of the \\ text's logic on outhor's intentions. \\ Kog-words outhor, writer; manuscripts; variants
}

